\title{
Author Index, Abstracts
}

\section{Numbers refer to Abstract Numbers}

Amato, M. 5 Babnik,J. 19 Bahlmann, H. 6 Berggren, P. 2 Bregant,L. 19 Burri, P. 5 Casiraghi, G. 18 Curstedt, T. 6 Desfréres, L. 12 Dolfin,T. 11 Doyle, C. 5 Fahat,M. 12 Feet, B.A. 10 Frantz, I. 5 Goetze-Speer, B. 14 Greisen, G. 15 Groneck, P. 14 Herting, E. 7 Johansson, J. 1 Koppe, J.G. 13 Kornhauser-Cerar, L. 19 Kuint,J. 11 Landeghem, K. van 13 Lee, M.M. 3 Lekka,M. 8 Linderholm, B. 2 Marraro, G. 18 Megreli, Ch. 17 Moen,A. 9, 10 Nielsen, H. 5 Obladen,M. 8 Papagaroufalis, C. 17 Pinder,R.S. 4 Putz, G. 3 Relier,J.P. 12 Robertson, B. 6, 7 Rootwelt,T. 9 Saugstad, O.D. 9. 10 Scheid,A. 8 Schipper, J.A. 13 Schürch, S. 3 Segerer, H. 8 Shinwell, E.S. 11 Sonderen, L. v. 13 Speer,Ch.P. 14 Strayer, D. 7 Strayer, D.S. 4 Sun,B. 6,7, 16 Thomas, A.P. 4 Wagner, M.H. 8 Walti, H. 12 Xanthou, M. 17 Xing,Q.-S. 16 Yang,Y. 16 Yu.X.-Q. 9, 10 Zhang, S.-T. 16

224

Biol Neonate 1996;69:213-224

11 th Workshop on Surfactant Replacement 